\title{
Prognosis of patients with heart failure and reduced ejection fraction in China
}

\author{
YU XU*, YANAN SHI ${ }^{*}$, ZHONGYU ZHU, CHANGHE CUI, BEI LI, \\ FANG CHEN, DAN LI, SONGHU CHEN and YANG GUO

\begin{abstract}
Department of Cardiology, Henan Province People's Hospital, The People's Hospital of Zhengzhou University, Zhengzhou, Henan 450003, P.R. China
\end{abstract}

Received May 7, 2013; Accepted September 9, 2013

DOI: $10.3892 /$ etm.2013.1341

\begin{abstract}
The present study aimed to investigate the 5-year survival and medication status of patients with chronic heart failure (HF) and reduced ejection fraction (HFrEF) in China. This study is a single-center, retrospective study and patients with HF and a left ventricular ejection fraction (LVEF) of $\leq 45 \%$, were consecutively enrolled. The study population of 685 patients was divided into two groups, namely, LVEF $\leq 35$ $(n=371)$ and LVEF 36-45\% $(n=314)$. The patients were followed up for a median of 31 months (range, 8-61 months) and during this period, $24 \%$ of patients receiving angiotension-converting enzyme inhibitor/angiotensin receptor blocker (ACEI/ARB) treatment and $23 \%$ of those receiving $\beta$-blockers reached the maximum tolerated dose. Of the 191 total mortalities (28\%), 127 were due to pump failure (19\%) and $42(6 \%)$ were sudden deaths. A Cox proportional hazards regression model was used to identify the variables associated with the risk of mortality. Kaplan-Meier curves and log-rank tests were used to compare the survival times of patients in the LVEF $\leq 35 \%$ and LVEF of $36-45 \%$ groups. The predictors of all-cause mortality were advanced age, body mass index, New York Heart Association functional class and lack of oral $\beta$-blockers at discharge. Patients with HFrEF have poor prognoses in China, particularly those patients with an LVEF of $\leq 35 \%$. Therefore, cardiologists should strive to improve the prognosis of HF among Chinese patients and focus on the importance of the practical application of HF diagnosis and treatment guidelines.
\end{abstract}

Correspondence to: Professor Zhongyu Zhu, Department of Cardiology, Henan Province People's Hospital, The People's Hospital of Zhengzhou University, Zhengzhou, Henan 450003, P.R. China

E-mail: zhongyuzhucn@126.com

*Contributed equally

Key words: heart failure, prognosis, left ventricular ejection fraction, medication status quo

\section{Introduction}

Heart failure (HF) is a modern epidemic and a significant public health problem. Patients with HF are frequently hospitalized and have a high mortality rate. Regardless of the remarkable advances in diagnosis and therapy over the past decade, the prognosis of patients with HF remains poor, with mortality rates approaching $20 \%$ per year (1). With changing epidemiological and socioeconomical developments, the epidemiology characteristics of HF in developing and developed countries are becoming increasingly similar, such that coronary heart disease as HF etiology is increasingly prominent in China $(2,3)$. However, the overall profile and prognosis of patients with $\mathrm{HF}$ and reduced ejection fraction (HFrEF) is very limited (4). Most Chinese cardiologists are challenged with the high mortality rate of patients with HFrEF. The present study retrospectively analyzed a cohort of 685 Chinese patients to clarify the overall profile and prognosis of HFrEF. A left ventricular ejection fraction (LVEF) of $\leq 45 \%$ is defined as a significantly reduced LVEF (4).

\section{Subjects and methods}

Study groups. A total of 748 patients were admitted to the Department of Cardiology, Henan Provincial People's Hospital (Zhengzhou, China) from June 14, 2007 to January 27, 2012. Patients were diagnosed with HF according to the modified Framingham criteria for HF (5) and an LVEF of $\leq 45 \%$ was determined by echocardiography during hospitalization. Patients were excluded from this study if they had recent acute coronary syndrome, acute viral myocarditis, congenital heart disease or severe heart valve disease. In addition, patients that had other concomitant diseases that are associated with a reduced life expectancy, including malignant tumors, severe hematological system disorders, chronic respiratory failure and end-stage cirrhosis, were excluded. Sixty-three patients (9\%) who had incomplete clinical data or were lost during the follow-up period, were also excluded from this study. The study population consisted of 685 patients with HF, divided into two groups: patients with an LVEF of $\leq 35 \%(n=371)$ or an LVEF of 36-45\% $(n=314)$. Moreover, if the patient was hospitalized more than once due to HF, only the data from the first hospitalization was analyzed. This study was conducted in 
accordance with the Declaration of Helsinki and with approval from the ethics committee and the Institutional Review Board of Henan Provincial People's Hospital (Zhengzhou, China). Written informed consent was obtained from all participants.

Data extraction. The data relating to the demographic status of patients, including age, gender, body weight, height, place of residence, admission date, cause of admission, background (concurrent) diseases, drug use during hospitalization and drug prescription on discharge, were recorded systematically from the medical records during hospitalization. Body mass index (BMI) was calculated using the following equation: $\mathrm{BMI}=$ body weight $(\mathrm{kg}) /[\text { height }(\mathrm{m})]^{2}$. Moreover, the estimated glomerular filtration rate (eGFR) was calculated as described in a previous study (6) using the following equation: eGFR = 1 86 x SCr-1.154 x age- 0.203 (x 0.742 if female) $\mathrm{ml} / \mathrm{min} / 1.73 \mathrm{~m}^{2}$.

Study endpoints. The study endpoints included registration for total mortality and sudden or pump failure death. Mortality was defined as sudden if it occurred within $24 \mathrm{~h}$ in the absence of pre-existing progressive circulatory failure or other causes of mortality, as well as if a witnessed death occurred within $60 \mathrm{~min}$ of the emergence of new symptoms. Pump failure death was defined as those occurring due to refractory progressive end-stage HF.

Follow-up. Information regarding the clinical outcome was collected from the patients, dependents of patients or referring physician via telephone interviews, letters or clinical visits.

Statistical analysis. Statistical analyses were performed using SPSS software, version 13.0 (SPSS, Inc., Chicago, IL, USA). Data are presented as the mean \pm standard deviation or median for continuous data and the significance was analyzed using a two-sampled t-test. Categorical variables were described in terms of frequencies and percentages and tested using a Chi-square or a Fisher's exact test when the theoretical frequency was $\geq 1$ or $<5$. Cox proportional hazards regression analysis for time of death was used to identify the factors associated with the increased risk of mortality. A forward step method was used to define the final model and the independent predictors of mortality. Results are presented as hazard ratios (HR) and 95\% confidence intervals (CI) for each covariate in the model. The Kaplan-Meier survival curves were plotted and the groups were compared using the log-rank test. All P-values were calculated from a 2 -tailed test and $\mathrm{P}<0.05$ was considered to indicate a statistically significant difference.

\section{Results}

Clinical parameters. The baseline characteristics of the 685 patients in this study are shown in Table I. Patients with an LVEF of $\leq 35 \%$ had a significantly higher heart rate $(87 \pm 19$ versus $80 \pm 15 \mathrm{bpm}, \mathrm{P}=0.000)$, increased incidence of ventricular tachycardia (18 versus $12 \%, \mathrm{P}=0.021)$, New York Heart Association (NYHA) classes III (41 versus 32\%, $\mathrm{P}=0.017$ ) and IV (30 versus $17 \%, \mathrm{P}=0.000$ ) upon admission, than the patients with LVEFs of 36-45\%. Compared to ejection fraction of $36 \%-45 \%$ of the patients, the ejection fraction $\leq 35 \%$ of patients with low serum sodium $(140 \pm 4$ versus $141 \pm 5 \mathrm{mmol} / \mathrm{l}$,
$\mathrm{P}=0.049)$. Furthermore, patients with an LVEF of $\leq 35 \%$ were less likely to be receiving aspirin (62 versus $73 \%, \mathrm{P}=0.003$ ), nitrates (45 versus $54 \%, \mathrm{P}=0.018$ ), statins (32 versus $49 \%$, $\mathrm{P}=0.000)$ and clopidogrel (10 versus $23 \%, \mathrm{P}=0.000)$, but more likely to be taking diuretics (93 versus $85 \%, \mathrm{P}=0.001$ ), digoxin ( 89 versus $70 \%, \mathrm{P}=0.000$ ), spironolactone ( 86 versus $78 \%, \mathrm{P}=0.009)$, coenzyme $\mathrm{Q} 10$ (33 versus $23 \%, \mathrm{P}=0.004)$ and stem cells (13 versus $6 \%, \mathrm{P}=0.004)$. In addition, patients with an LVEF of $\leq 35 \%$ had a higher incidence rate of left bundle branch block ( $9 \%$ vs. $5 \%, \mathrm{P}=0.041)$, as well as a larger left ventricular end-diastolic dimension $(69 \pm 9$ versus $64 \pm 8 \mathrm{~mm}$, $\mathrm{P}=0.000)$.

Survival analysis. The patients were followed up for a median of 31 months (range, 8-61 months). A total of 191 mortalities $(28 \%)$ were recorded, 127 of which were due to pump failure (19\%) and 42 were sudden deaths (6\%). The all-cause mortality rate was $37 \%(n=137)$ among patients with an LVEF of $\leq 35 \%$, which was significantly higher compared with $17 \%(n=54)$ in patients with LVEFs of $36-45 \%(P=0.000)$. Pump failure death occurred in 25 and $12 \%$ of patients with LVEFs of $\leq 35$ and $36-45 \%$, respectively $(\mathrm{P}=0.000)$. Moreover, sudden death occurred in 8 and $4 \%$ of patients with LVEFs of $\leq 35$ and $36-45 \%$, respectively $(\mathrm{P}=0.046)$. The unadjusted mortality rates from all causes and the Kaplan-Meier estimated survival for the two groups are summarized in Table II. The Kaplan-Meier estimated survival curve for all patients is shown in Fig. 1, with 3, 4 and 5-year survival rates of 71, 56 and $34 \%$, respectively. The Kaplan-Meier estimated survival curves for the two groups are shown in Fig. 2, with 3, 4 and 5 -year survival rates of 61,47 and $25 \%$, respectively, in patients with an LVEF of $\leq 35 \%$ and 83, 66 and $46 \%$, respectively, in patients with an LVEF of 36-45\% ( $\mathrm{P}=0.000$ log-rank test).

Kaplan-Meier curves describing the cumulative survival probability of time to occurrence of pump failure death for the two groups, is represented in Fig. 3 ( $\mathrm{P}=0.000$ log-rank test).

Using the recommended BMI classified according to the Working Group of China Obesity (7), the patients were divided into four groups: Low weight $\left(\mathrm{BMI}<18.5 \mathrm{~kg} / \mathrm{m}^{2}\right)$, normal weight $\left(18.5 \leq \mathrm{BMI}<24.0 \mathrm{~kg} / \mathrm{m}^{2}\right)$, overweight $\left(24.0 \leq \mathrm{BMI}<28.0 \mathrm{~kg} / \mathrm{m}^{2}\right)$ and obese $\left(\mathrm{BMI} \geq 28.0 \mathrm{~kg} / \mathrm{m}^{2}\right)$. The all-cause mortality rate significantly increased with a reduction in $\mathrm{BMI}(\mathrm{P}=0.000$; Fig. 4).

The N-terminal pro-brain natriuretic peptide (NT-proBNP) median level was $2,517 \mathrm{pg} / \mathrm{ml}$. The study population was divided into two groups: NT-ProBNP $\leq 2,517$ and $>2,517 \mathrm{pg} / \mathrm{ml}$. The all-cause mortality rate significantly increased with an increasing NT-ProBNP median level ( $\mathrm{P}=0.003$; Fig. 5).

The predictors of the all-cause mortality rate among the study patients were advanced age and BMI, as well as the lack of oral $\beta$-blockers at discharge and NYHA functional class. The results of these multivariate analyses are reported in Table III.

Medication status quo. During the follow-up period, 24\% of the patients who continued to receive angiotension-converting enzyme inhibitor/angiotensin receptor blocker (ACEI/ARB) treatment and $23 \%$ of those on $\beta$-blockers were taking the maximum tolerated dose. In addition, 17 and $9 \%$ were taking the recommended target doses, 47 and $20 \%$, were taking $\geq 50$ to $<100 \%$ of the target dose, 30 and $36 \%$ were receiving $\geq 25$ 
Table I. Clinical characteristics of the study patients.

\begin{tabular}{|c|c|c|c|c|}
\hline Parameter & $\begin{array}{l}\text { All patients } \\
(\mathrm{n}=685)\end{array}$ & $\begin{array}{c}\mathrm{LVEF} \leq 35 \% \\
\quad(\mathrm{n}=371)\end{array}$ & $\begin{array}{l}\text { LVEF } 36-45 \% \\
\quad(\mathrm{n}=314)\end{array}$ & P-value \\
\hline Male & $462(67)$ & 255 (69) & $207(66)$ & 0.434 \\
\hline Age (year) & $57 \pm 16$ & $56 \pm 16$ & $59 \pm 15$ & 0.032 \\
\hline $\operatorname{BMI}\left(\mathrm{kg} / \mathrm{m}^{2}\right)$ & $24 \pm 4$ & $23 \pm 4$ & $24 \pm 4$ & 0.004 \\
\hline $\mathrm{SBP}(\mathrm{mmHg})$ & $124 \pm 21$ & $122 \pm 21$ & $128 \pm 21$ & 0.000 \\
\hline $\mathrm{DBP}(\mathrm{mmHg})$ & $80 \pm 13$ & $79 \pm 14$ & $81 \pm 13$ & 0.104 \\
\hline HR (beats per min) & $84 \pm 18$ & $87 \pm 19$ & $80 \pm 15$ & 0.000 \\
\hline Hemoglobin (g/l) & $128 \pm 19$ & $129 \pm 19$ & $126 \pm 19$ & 0.012 \\
\hline $\operatorname{ALT}(\mathrm{U} / \mathrm{l})$ & $66 \pm 272$ & $83 \pm 350$ & $46 \pm 127$ & 0.066 \\
\hline $\operatorname{AST}(\mathrm{U} / \mathrm{l})$ & $60 \pm 379$ & $78 \pm 506$ & $38 \pm 107$ & 0.136 \\
\hline Uric acid $(\mu \mathrm{mol} / \mathrm{l})$ & $416 \pm 134$ & $422 \pm 137$ & $409 \pm 129$ & 0.206 \\
\hline Serum sodium (mmol/l) & $140 \pm 5$ & $140 \pm 4$ & $141 \pm 5$ & 0.049 \\
\hline Ischemic cardiomyopathy & $287(42)$ & $123(33)$ & $164(52)$ & 0.000 \\
\hline Atrial fibrillation & $121(18)$ & $63(17)$ & $58(19)$ & 0.610 \\
\hline Hypertension & $223(33)$ & $95(26)$ & $128(41)$ & 0.000 \\
\hline Diabetes mellitus & $118(17)$ & $60(16)$ & $58(19)$ & 0.427 \\
\hline Smoking & $190(28)$ & $100(27)$ & $90(29)$ & 0.619 \\
\hline Ventricular tachycardia ${ }^{\mathrm{a}}$ & $102(15)$ & $66(18)$ & $36(12)$ & 0.021 \\
\hline ICD implant & $15(2)$ & $11(3)$ & $4(1)$ & 0.132 \\
\hline CRT implant & $23(3)$ & $14(4)$ & $9(3)$ & 0.511 \\
\hline Stem cell & $68(10)$ & $48(13)$ & $20(6)$ & 0.004 \\
\hline \multicolumn{5}{|l|}{ KD stage } \\
\hline $1(\geq 90)$ & $256(37)$ & $140(38)$ & $116(37)$ & 0.831 \\
\hline $2(60-89)$ & $293(43)$ & $163(44)$ & $130(41)$ & 0.504 \\
\hline $3(30-59)$ & $124(18)$ & $62(17)$ & $62(20)$ & 0.304 \\
\hline $4(15-29)$ & $6(1)$ & $2(1)$ & $4(1)$ & 0.421 \\
\hline $5(<15)$ & $6(1)$ & $4(1)$ & $2(1)$ & 0.693 \\
\hline \multicolumn{5}{|l|}{ NYHA class } \\
\hline II & 267 (39) & 107 (29) & $160(51)$ & 0.000 \\
\hline III & $253(37)$ & $152(41)$ & $101(32)$ & 0.017 \\
\hline IV & $165(24)$ & $112(30)$ & $53(17)$ & 0.000 \\
\hline \multicolumn{5}{|l|}{ Medications at discharge } \\
\hline ACE inhibitor/ARB & $569(83)$ & $309(83)$ & $260(83)$ & 0.866 \\
\hline$\beta$-blockers & $555(81)$ & $302(81)$ & $253(81)$ & 0.783 \\
\hline Digoxin & $550(80)$ & $331(89)$ & $219(70)$ & 0.000 \\
\hline Diuretics & $609(89)$ & $343(93)$ & $266(85)$ & 0.001 \\
\hline Nitrates & $333(49)$ & $165(45)$ & $168(54)$ & 0.018 \\
\hline Spirolactone & $563(82)$ & $318(86)$ & $245(78)$ & 0.009 \\
\hline Aspirin & $458(67)$ & $230(62)$ & $228(73)$ & 0.003 \\
\hline Statins & $272(40)$ & $118(32)$ & $154(49)$ & 0.000 \\
\hline Clopidogrel & $110(16)$ & $37(10)$ & $73(23)$ & 0.000 \\
\hline Coenzyme Q10 & $196(29)$ & $123(33)$ & $73(23)$ & 0.004 \\
\hline Sinus rhythm & $544(79)$ & $296(80)$ & $248(79)$ & 0.796 \\
\hline
\end{tabular}


Table I. Continued.

\begin{tabular}{|c|c|c|c|c|}
\hline Parameter & $\begin{array}{l}\text { All patients } \\
\qquad(\mathrm{n}=685)\end{array}$ & $\begin{array}{c}\mathrm{LVEF} \leq 35 \% \\
(n=371)\end{array}$ & $\begin{array}{l}\text { LVEF } 36-45 \% \\
\qquad(n=314)\end{array}$ & P-value \\
\hline \multicolumn{5}{|c|}{ Conduction block } \\
\hline LBBB & $50(7)$ & $34(9)$ & $16(5)$ & 0.041 \\
\hline RBBB & $31(5)$ & $16(4)$ & $15(5)$ & 0.771 \\
\hline LVEF (\%) & $34 \pm 7$ & $28 \pm 6$ & $40 \pm 2$ & 0.000 \\
\hline LVEDD (mm) & $68 \pm 9$ & $69 \pm 9$ & $64 \pm 8$ & 0.000 \\
\hline
\end{tabular}

Data are presented as mean \pm standard deviation or as a frequency and percentage in parentheses. BMI, body mass index; SBP, systolic blood pressure; DBP, diastolic blood pressure; HR, heart rate (evaluated or measured at admission); ALT, alanine aminotransferase; AST, aspartate aminotransferase; ICD, implantable cardioverter-defibrillator; CRT, cardiac resynchronization therapy; eGFR, estimated glomerular filtration rate; CKD, chronic kidney disease; NYHA, New York Heart Association; ACE, angiotension-converting enzyme; ARB, angiotensin receptor blocker; LBBB, left bundle branch block; RBBB, right bundle branch block; LVEF, left ventricular ejection fraction; RBBB, right bundle branch block; LVEF, left ventricular ejection fraction; LVEDD, left ventricular end-diastolic dimension. ${ }^{\text {a }}$ Including sustained and non-sustained ventricular tachychardia.

Table II. Unadjusted all-cause mortality and Kaplan-Meier estimated survival rates.

\begin{tabular}{|c|c|c|c|c|}
\hline Survival rates $(\%)$ & $\begin{array}{l}\text { All patients } \\
(\mathrm{n}=685)(\%)\end{array}$ & $\begin{array}{l}\mathrm{LVEF} \leq 35 \% \\
(\mathrm{n}=371)(\%)\end{array}$ & $\begin{array}{c}\text { LVEF } 36-45 \% \\
(n=314)(\%)\end{array}$ & $\mathrm{P}$-value \\
\hline All-cause mortality & $191(28)$ & $137(37)$ & $54(17)$ & 0.000 \\
\hline 3-year survival & 71 & 61 & 83 & $0.000^{\mathrm{a}}$ \\
\hline 4-year survival & 56 & 47 & 66 & - \\
\hline 5-year survival & 34 & 25 & 46 & - \\
\hline
\end{tabular}

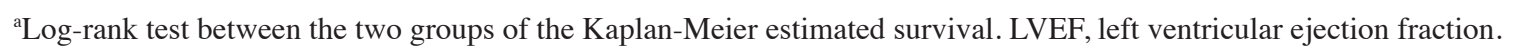

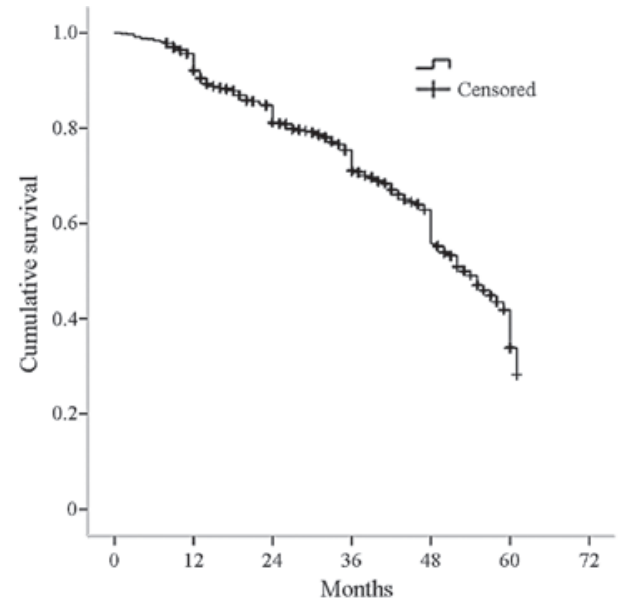

Figure 1. Kaplan-Meier estimated survival curve for the study population.

to $<50 \%$ of the target dose and 7 and $35 \%$ were taking $<25 \%$ of the target dose.

\section{Discussion}

The present study examined the clinical characteristics and outcomes of Chinese patients with HF and an LVEF of

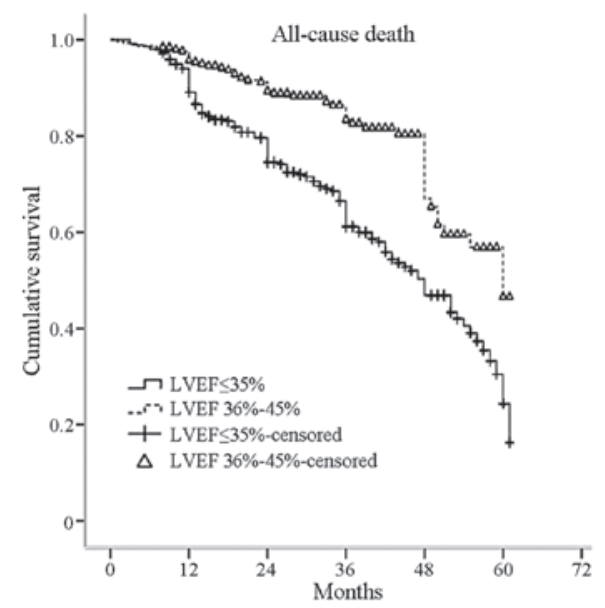

Figure 2. Kaplan-Meier estimated survival curves for the two groups with different left ventricular ejection fraction (LVEF) values $(\mathrm{P}=0.000$ log-rank test).

$\leq 45 \%$. The main findings were as follows: The predictors for all-cause mortality were advanced age, NYHA class, BMI and lack of $\beta$-blockers at discharge; the all-cause mortality for the entire study population was $28 \%$ during the median follow-up period of 31 months and the 5-year survival rate of patients with HF and LVEFs of $\leq 35$ and $36-45 \%$, were 25 and 


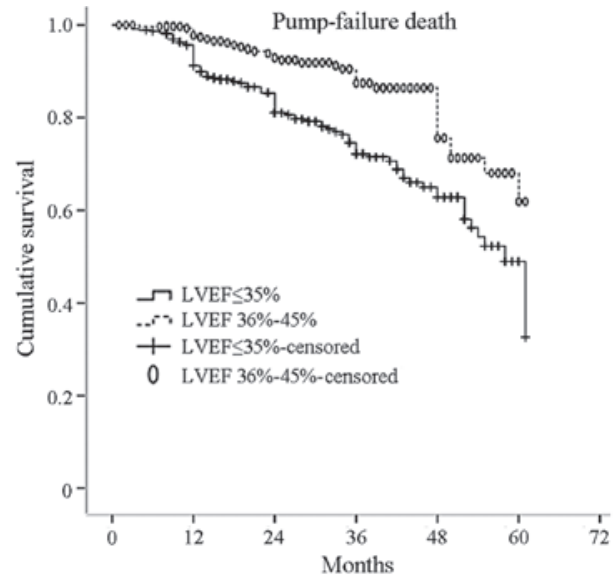

Figure 3. Kaplan-Meier estimated survival curves for the two groups with different left ventricular ejection fraction ( $\mathrm{LVEF}$ ) values $(\mathrm{P}=0.000$ log-rank test).

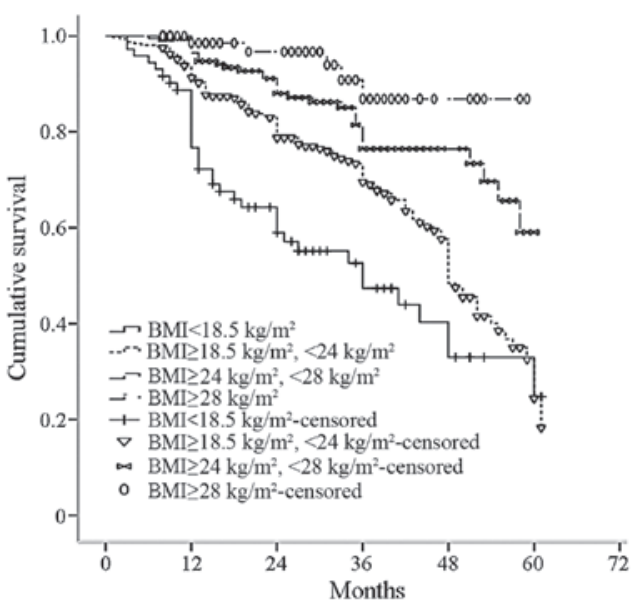

Figure 4. Kaplan-Meier estimated survival curves for four groups with different body mass indices (BMIs) ( $\mathrm{P}=0.000$ log-rank test).

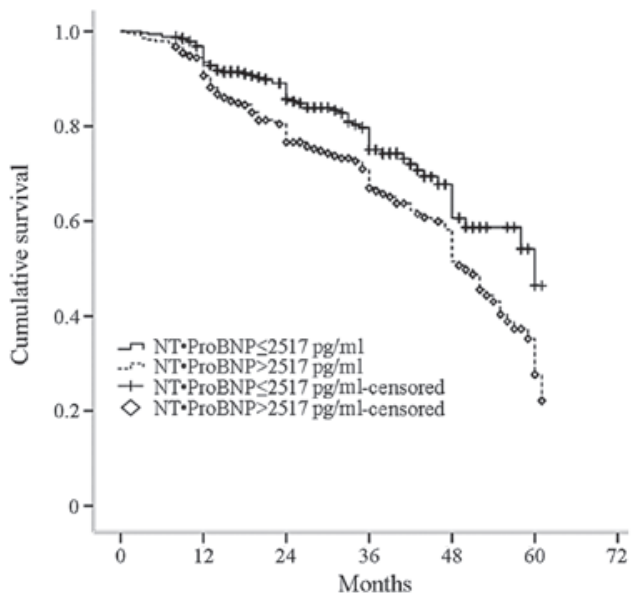

Figure 5. Kaplan-Meier estimated survival curves for two groups with different $\mathrm{N}$-terminal pro-brain natriuretic peptide (NT•proBNP) levels $(\mathrm{P}=0.003$ log-rank test $)$.

$46 \%$, respectively; and up to $42 \%$ of the patients had ischemic cardiomyopathy and $>80 \%$ of patients were taking $\beta$-blockers, ACEI/ARB, aspirin and diuretics at discharge.
Table III. Predictors of all-cause mortality after Cox analyses.

\begin{tabular}{lcc}
\hline Parameter & $\begin{array}{c}\text { Hazard Ratio } \\
(95 \% \mathrm{CI})\end{array}$ & P-value \\
\hline Age (per increased 1 year) & $1.03(1.02-1.04)$ & 0.000 \\
NYHA (per increased 1 class) & $1.59(1.32-1.92)$ & 0.000 \\
$\beta$-blockers at discharge & $0.69(0.50-0.95)$ & 0.021 \\
BMI & $0.58(0.48-0.72)$ & 0.000 \\
LVEF 36-45\% & $0.52(0.38-0.71)$ & 0.000 \\
\hline
\end{tabular}

NYHA, New York Heart Association; BMI, body mass index; LVEF, left ventricular ejection fraction; CI, confidence interval.

The European Society of Cardiology (ESC) integrated data from 51 countries and demonstrated there are $\geq 15$ million cases of HF among 1 billion patients, as well as a considerable number of patients with asymptomatic heart dysfunction (8). The American Heart Association (AHA) identified that $>5$ million patients have HF in the United States, a number that continues to increase by 550,000 patients per year ${ }^{1}$. Furthermore, in Japan, the 3-year mortality of patients with HF was reported in 2008 to be $29.2 \%$ (9). The situation in Europe is not optimistic, with a 4-year survival rate of only $50 \%$ and $40 \%$ of the patients admitted to hospitals due to $\mathrm{HF}$ are readmitted or die within 1 year of treatment $(10,11)$. In the Framingham Heart study, $75 \%$ of men and $62 \%$ of women succumbed during the 5-year follow-up time (12). In the current study, the 5-year survival rate of patients was $34 \%$, similar to the findings by Rochester and colleagues in 1991 (13), who noted a 5-year survival rate of 33\% among patients with HF during the 10 -year follow-up period. The predictors of mortality demonstrated in the current study are consistent with previous reports $(9,14)$. McDonagh et al (15) confirmed that, even for asymptomatic patients, the BNP mass concentration was slightly elevated ( $\geq 17.9 \mathrm{ng} / \mathrm{l})$, the risk of mortality increased by two-fold (hazard ratio of 2.2) and that LVEF is an important predictor of mortality. The COPERNICUS (16) NT-pro BNP substudy indicated that NT-pro BNP levels above the median $(>1,767 \mathrm{pg} / \mathrm{ml})$ on admission were independently associated with an increased risk of all-cause mortality during follow-up. Simultaneously, the meta-analysis conducted by Doust et al (17) showed that the BNP mass concentration is closely related to the prognosis of patients with HF. For each additional $100 \mathrm{ng} / \mathrm{l}$ increase in BNP mass concentration, a $35 \%$ increase in the relative risk of mortality was observed. Additionally, Zamora et al (18) assessed the relationship between BMI and survival over a long-term follow-up period of ischemic and non-ischemic HF and concluded that the obesity paradox was only observed in patients with non-ischemic HF. In the MERIT-HF (19) and CIBIS-II (20) trials, $\beta$-blockers reduced mortality and sudden cardiac death (SCD), and metoprolol and bisoprolol reduced the all-cause mortality by $34 \%$. A further study (21) demonstrated that carvedilol significantly reduced mortality by $35 \%$ $(\mathrm{P}=0.0014)$. The results of the three large-scale clinical trials indicate that $\beta$-blockers significantly improved the prognosis, 
showing a significant reduction in total mortality (34-35\%) and sudden death (41-45\%). It may be suggested that $\beta$-blockers are indispensible in the treatment of HF; thus, patients should be prescribed the recommended dose to suppress excessive activation of the sympathetic nervous system, improve cardiac remodeling and reduce sudden death. However, in clinical practice, the application of ACEI/ARB, $\beta$-blockers and heart failure treatment guidelines still have a diverse gap; therefore, these therapies should be used widely and consistently. The Chinese Medical Society of Cardiology retrospectively analyzed and compared results of 42 hospitals in 1980, 1990 and 2000 heart failure hospitalization records, and observed that in 2000 the ACEI use ratio was $40.4 \%$ in China. The use of $\beta$-blockers was $<20 \%$, far less than in the United States and Europe in the 1990s (from 60 to 90\%). In addition, ARB use was only $4.5 \%$ (22). Cao et al (23) examined 17 regions in China and demonstrated that $10 \%$ of patients received high-dose digoxin ( $\geq 0.125 \mathrm{mg} /$ day), $90 \%$ of symptomatic patients with chronic HF were prescribed diuretics and $80 \%$ of patients received ACEI. The recommended dose application rate was only $2 \%$, the use of $\beta$-blockers was $40 \%$ and the rate of application of the recommended dose was only $1 \%$. The present study had a small sample size and was a single-center study; therefore, the results may not be applicable to other regions of China.

In China, patients with $\mathrm{HFrEF}$ have a poor prognosis, particularly those with an LVEF of $\leq 35 \%$. Cardiologists should aim to improve the prognosis of HF among Chinese patients and focus on the importance of diagnosis and treatment. Guidelines for the practical application and recommended use of treatment agents should be provided and efforts made to reach the recommended target dose or the maximum tolerated dose in patients.

\section{References}

1. Rosamond W, Flegal K, Friday G, et al; American Heart Association Statistics Committee and Stroke Statistics Subcommittee: Heart disease and stroke statistics - 2007 update: a report from the American Heart Association Statistics Committee and Stroke Statistics Subcommittee. Circulation 115: e69-e171, 2007.

2. Mendez GF and Cowie MR: The epidemiological features of heart failure in developing countries: a review of the literature. Int J Cardiol 80: 213-219, 2001

3. World Health Organization: Cardiovascular disease: prevention and control (EB/OL). http://www.who.int/dietphysicalactivity/publications/facts/cvd/en/. Accessed March 07, 2010.

4. Cheng Z, Zhu K, Chen T, et al: Poor prognosis in chronic heart failure patients with reduced ejection fraction in China. Congest Heart Fail 18: 165-172, 2012.

5. McKee PA, Castelli WP, McNamara PM and Kannel WB: The natural history of congestive heart failure: the Framingham study. N Engl J Med 285: 1441-1446, 1971.

6. National Kidney Foundation: K/DOQI clinical practice guidelines for chronic kidney disease: evaluation, classification, and stratification. Am J Kidney Dis 39 (2 Suppl 1): S1-S266, 2002.
7. Zhou B; Cooperative Meta-Analysis Group of China Obesity Task Force: Predictive values of body mass index and waist circumference to risk factors of related diseases in Chinese adult population. Chinese Journal of Epidemiology 23: 5-10, 2002 (In Chinese).

8. Dickstein K, Cohen-Solal A, Filippatos G, et al; ESC Committee for Practice Guidelines (CPG): ESC guidelines for the diagnosis and treatment of acute and chronic heart failure 2008: the Task Force for the diagnosis and treatment of acute and chronic heart failure 2008 of the European Society of Cardiology. Developed in collaboration with the Heart Failure Association of the ESC (HFA) and endorsed by the European Society of Intensive Care Medicine (ESICM). Eur J Heart Fail 10: 933-989, 2008.

9. Kawashiro N, Kasanuki H, Ogawa H, Matsuda N and Hagiwara N; Heart Institute of Japan - Department of Cardiology (HIJC) Investigators: Clinical characteristics and outcome of hospitalized patients with congestive heart failure: results of the HIJC-HF registry. Circ J 72: 2015-2020, 2008.

10. Cowie MR, Wood DA, Coats AJ, et al: Survival of patients with a new diagnosis of heart failure: a population based study. Heart 83: 505-510, 2000.

11. Stewart S, MacIntyre K, Hole DJ, Capewell S and McMurray JJ: More 'malignant' than cancer? Five-year survival following a first admission for heart failure. Eur J Heart Fail 3: 315-322, 2001.

12. Ho KK, Anderson KM, Kannel WB, Grossman W and Levy D: Survival after the onset of congestive heart failure in Framingham Heart Study subjects. Circulation 88: 107-115, 1993.

13. Senni M, Tribouilloy CM, Rodeheffer RJ, et al: Congestive heart failure in the community: trends in incidence and survival in a 10-year period. Arch Intern Med 159: 29-34, 1999.

14. Levy WC, Mozaffarian D, Linker DT, et al: The Seattle Heart Failure Model: prediction of survival in heart failure. Circulation 113: 1424-1433, 2006.

15. McDonagh TA, Cunninghanl AD, Morrison CE, et al: Left ventricular dysfunction, natriuretic peptides, and mortality in an urban population. Heart 86: 21-26, 2001.

16. Hartmann F, Packer M, Coats AJ, et al: Prognostic impact of plasma N-terminal pro-brain natriuretic peptide in severe chronic congestive heart failure: a substudy of the Carvedilol Prospective Randomized Cumulative Survival (COPERNICUS) trial. Circulation 110: 1780-1786, 2004.

17. Doust JA, Pietrzak E, Dobson A and Glasziou P: How well does B-type natriuretic peptide predict death and cardiac events in patients with heart failure: systematic review. BMJ 330: 625, 2005.

18. Zamora E, Lupón J, de Antonio M, et al: The obesity paradox in heart failure: Is etiology a key factor? Int J Cardiol 166, 601-605, 2013.

19. No authors listed: Effect of metoprolol CR/XL in chronic heart failure: Metoprolol CR/XL Randomised Intervention Trial in Congestive Heart Failure (MERIT-HF). Lancet 353: 2001-2007, 1999.

20. No authors listed: The Cardiac Insufficiency Bisoprolol Study II (CIBIS-II): a randomized trial. Lancet 353: 9-13, 1999.

21. Packer M, Fowler M and Rouleau J, et al: COPERNICUS (carvedilol prospective randomized cumulative survival trial): A multicenter randomized double-blind placebo-controlled study to determine the effect of carvedilol on mortality in severe congestive heart failure. Cardiovasc Drugs Ther 13: 24, 1999.

22. Society of Cardiology, Chinese Medical Association: Retrospective investigation of hospitalized patients with heart failure in some parts of China in 1980, 1990 and 2000. Chinese Journal of Cardiology 30: 450-454, 2002 (In Chinese).

23. Cao YM, Hu DY, Wang HY and Wu Y: A survey of medical therapies for chronic heart failure in primary hospitals in China. Chinese Journal of Internal Medicine 45: 907-909, 2006 (In Chinese). 